\title{
TERAPIA ANTIRRETROVIRAL EN ADULTOS INFECTADOS POR VIH
}

Carlos A. DíazGranados, $M D, M S^{*}$

\section{Resumen}

La infección por VIH es de importancia global y local. La terapia antirretroviral altamente activa (HAART) ha modificado dramáticamente la historia natural de la infección por VIH, convirtiéndola en una enfermedad crónica controlable. En Colombia el Plan Obligatorio de Salud (POS) obliga a las Empresas Prestadoras de Salud (EPS) a que sus afiliados tengan acceso a HAART. EI momento ideal para iniciar terapia antirretroviral es motivo de controversia. El prestador de salud puede tomar sus decisiones adaptando las guías de la Organización Mundial de la Salud (OMS) o del Departamento de Salud de los Estados Unidos (DHHS). Actualmente existe evidencia de la superioridad y conveniencia de algunos regímenes antirretrovirales sobre otros, lo cual se ha reflejado en que algunos regímenes sean considerados preferenciales y otros alternativos. La selección del régimen antirretroviral inicial debe tener en cuenta la mejor evidencia disponible sobre eficacia y tolerancia, pero también debe considerar las condiciones locales del Sistema de Salud que en algunas circunstancias dificultan la utilización de ciertos medicamentos. Una vez iniciada la terapia, el paciente debe monitorizarse para evaluar posibles efectos adversos y la respuesta virológica, inmunológica y clínica. Los cambios en la terapia antirretroviral deben ser realizados con cautela, idealmente guiados por un experto en el manejo del VIH. Aunque las pruebas de resistencia viral son un instrumento valioso en la selección de fármacos para pacientes con falla terapéutica, su complejidad tecnológica y su costo dificultan que se use de manera rutinaria en nuestro medio. El cumplimiento a la terapia antirretroviral es probablemente el determinante más importante de respuesta óptima, y por lo tanto debe explorarse, reforzarse y, de ser necesario, corregirse en cada consulta del paciente.

Abreviaturas: VIH: Virus Inmunodeficiencia Humana, SIDA: Síndrome de Inmunodeficiencia Adquirida, OMS: Organización Mundial de la Salud, DHHS: Departamento de Salud de los Estados Unidos, EPS: Empresa Prestadora de Salud, NRTI: Inhibidores Nucleotidos de Transcriptasa, NNRTI: Inhibidores No - Nucleotidos de Transcriptasa, PI: Inhibidores de Proteasa, AZT: Zidovudina, D4T: Estavudina, 3TC: Lamivudina, ETC: Emtricitabina, DDI: Didanosina, ABC: Abacavir.

\section{Introducción}

La infección por VIH es de importancia global y local. Según estadísticas de UNAIDS, aproximadamente 4 de 1.000 colombianos están infectados con el virus del SIDA. ${ }^{1}$ Hace un poco más de una década, el diagnóstico de VIH era considerado como una sentencia de muerte, ya que el SIDA se consideraba una enfermedad casi $100 \%$ fatal. Sin embargo, con el advenimiento de la terapia antirretroviral altamente activa en el año 1996, la mortalidad por VIH/SIDA disminuyó en forma dramática (Figura 1).

En Colombia, el sistema de salud incluye dentro del Plan Obligatorio de Salud (POS) algunos de los medicamentos útiles para tratar la infección por VIH (Tabla

* Coordinador Investigaciones Facultad de Medicina, Fundación Universitaria de Ciencias de la Salud - Infectólogo Clínica Jorge Piñeros Corpas.
1). Por consiguiente, es obligación de las Empresas Prestadoras de Salud (EPS) permitir que sus afiliados tengan acceso a la terapia antirretroviral.

En la siguiente discusión, exploraremos las indicaciones para iniciar terapia antirretroviral, los regímenes para iniciar tratamiento en pacientes en quienes está indicada, la forma de monitorizar la terapia en pacientes que la usan, las normas generales sobre ajustes y cambios de terapia antirretroviral, y la importancia del cumplimiento en el éxito de la terapia antirretroviral.

Es importante tener en cuenta que este documento es una guía realizada en un momento en el tiempo, acerca de una entidad clínica que cambia muy rápido. Por lo tanto, es fundamental que el lector actualice la información aquí consignada con la disponible a partir de mediados del 2004. 
Tabla I. Principales antirretrovirales y su condición según el POS y

disponibilidad en nuestro medio.

\begin{tabular}{lll}
\hline Grupo & Antirretroviral & Condición \\
\hline Inhibidores nucleósidos de & Zidovudina (AZT) & POS \\
transcriptasa inversa (NRTI) & Estavudina (D4T) & POS \\
& Didanosina (DDI) & POS \\
& Didanosina (DDI) EC & No POS \\
& Lamivudina (3TC) & POS \\
& Abacavir (ABC) & No POS \\
& Tenofovir & No Disponible \\
\hline Inhibidores no-nucleósidos de & Nevirapina & POS \\
transcriptasa reversa (NNRTI) & Efavirenz & No POS \\
\hline Inhibidores de proteasa (PI) & Nelfinavir & POS \\
& Indinavir & POS \\
& Ritonavir & POS \\
& Amprenavir & No POS \\
& Atazanavir & No POS \\
& Saquinavir & No POS \\
\hline Inhibidores de fusión & Lopinavir/Ritonavir & No POS \\
& T-20 & No disponible
\end{tabular}

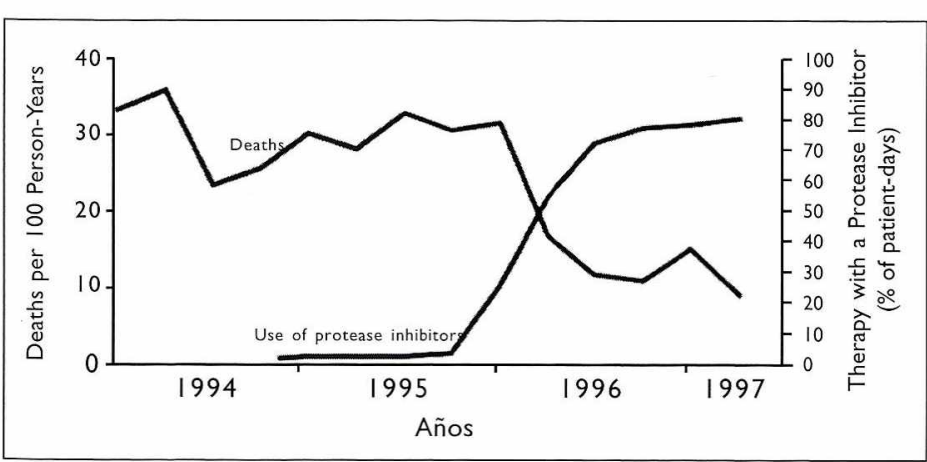

Figura I. Impacto de la terapia antirretroviral en la mortalidad por infección porVIH/SIDA. La columna vertical izquierda muestra el número de muertes por 100 personas/año; la columna vertical derecha muestra el porcentaje de pacientes tratados con inhibidores de proteasa. La línea horizontal baja muestra los años. (Tomado de Palella et al. N Engl J Med 1998; 338(|3):1998.853-860).

\section{Cuándo inícliar terapia antirretroviral}

El momento ideal para iniciar el tratamiento antirretroviral ha sido motivo permanente de controversia. De tratar "tarde" se pasó a tratar "temprano", y hace poco se ha considerado la opción de no tratar "ni tan tarde ni tan temprano".

La decisión de iniciar antirretrovirales debe balancear el riesgo de progresión a SIDA o muerte y el riesgo de desarrollar efectos adversos con potencialidad seria, derivados de la terapia antirretroviral. Si el riesgo de progresar a SIDA o muerte es muy alto, entonces está plenamente justificado iniciar terapia antirretroviral a pesar de su posible toxicidad. Sin embargo, si el tratamiento se inicia muy tarde, existe la posibilidad de que el paciente no pueda reconstituir su sistema inmunológico y por lo tanto permanezca en riesgo de complicaciones. Por otra parte, si el riesgo de progresión a SIDA o muerte es bajo, entonces no está justificado someter al paciente a los posibles efectos tóxicos de los medicamentos. Además, si el paciente se expone a antirretrovirales muy temprano, es de esperarse que el virus termine por desarrollar resistencia a esos medicamentos, y la selección, de regímenes terapéuticos en aquellos pacientes en quienes ha ocurrido falla del tratamiento, es más difícil y la respuesta mucho menos predecible. Todo lo anterior indica que el inicio de la terapia antirretroviral debe decidirse después de evaluar el riesgo de progresión de la enfermedad, de toxicidad por los medicamentos, la posibilidad de lograr reconstitución del sistema inmune y la disponibilidad de futuras alternativas terapéuticas. Es importante también tener en cuenta, so- 
bretodo en países en vía de desarrollo, que los recursos necesarios para iniciar la terapia antirretroviral temprana son mayores que los recursos necesarios para iniciarla menos temprana o tardíamente; y que el iniciar terapia antirretroviral tempranamente puede drenar los recursos del sistema de salud sin que necesariamente el paciente logre un beneficio relevante para su salud.

Existen diferentes documentos que buscan guiar la iniciación de la terapia antirretroviral. Los principales son los del Departamento de Salud de los Estados Unidos
(DHHS), ${ }^{2}$ y de la Organización Mundial de la Salud (OMS). ${ }^{3}$ Estos documentos no son mandatos y deben ser interpretados con precaución por los médicos tratantes.

Las guías para iniciar la terapia antirretroviral según el DHHS se resumen en la Tabla 2.

Las guías para iniciar terapia de la OMS se resumen en la Tabla 3a. La Tabla 3b especifica la estadificación de la infección por VIH que permite aplicar las recomendaciones de inicio de la terapia.

\begin{tabular}{|c|c|c|c|}
\hline Categoría clínica & Conteo CD4 & Carga viral & Recomendación \\
\hline $\begin{array}{l}\text { Sintomático (SIDA o } \\
\text { síntomas severos) }\end{array}$ & Cualquier valor & Cualquier valor & Tratar \\
\hline Asintomático & $<200$ & Cualquier valor & Tratar \\
\hline Asintomático & $200-350$ & Cualquier valor & Ofrecer tratamiento (controversial) \\
\hline Asintomático & $>350$ & $>55000$ & $\begin{array}{l}\text { Algunos expertos recomiendan } \\
\text { iniciar tratamiento, otros reco- } \\
\text { miendan esperar y monitorizar }\end{array}$ \\
\hline Aasintomático & $>350$ & $<55000$ & $\begin{array}{l}\text { La mayoría de expertos reco- } \\
\text { miendan esperar y monitorizar }\end{array}$ \\
\hline
\end{tabular}

Tabla 3a. Recomendaciones de inicio de terapia antirretroviral OMS - 2003 (3).

Si se dispone de pruebas de cuantificación de los linfocitos T CD4+, se recomienda efectuar un recuento basal y ofrecer tratamiento antirretroviral a los pacientes con:

- Enfermedad en estadio IV de la OMS, independientemente del recuento de linfocitos T CD4+

- Enfermedad en estadio III de la OMS (por ejemplo, emaciación porVIH, diarrea crónica de etiología desconocida, fiebre prolongada de etiología desconocida, tuberculosis pulmonar, infecciones bacterianas invasivas y recurrentes - candidiasis mucosa recurrente o persistente), considerando la posibilidad de utilizar los recuentos de linfocitos $T$ CD4+ $<350 / \mathrm{mm}^{3}$ como ayuda para la toma de decisiones ${ }^{a}$

- Enfermedad en los estadios I o II de la OMS, con recuento de linfocitos T CD4+ $\leq 200 / \mathrm{mm}^{3}$ b

Si no se dispone de pruebas de cuantificación de los linfocitos T CD4+, se recomienda ofrecer tratamiento antirretroviral a los pacientes con:

- Enfermedad en estadio IV de la OMS, independientemente del recuento de linfocitos totales

- Enfermedad en estadio III de la OMS (por ejemplo, emaciación por VIH, diarrea crónica de etiología desconocida, fiebre prolongada de etiología desconocida, tuberculosis pulmonar, infecciones bacterianas invasivas y recurrentes o candidiasis mucosa recurrente o persistente), independientemente del recuento de linfocitos totales ${ }^{c}$

- Enfermedad en estadio II con recuento de linfocitos totales $\leq 1200 / \mathrm{mm}^{3} \mathrm{~d}$

a Es aconsejable utilizar el recuento de linfocitos T CD4+ a modo de guía para establecer la necesidad de tratamiento inmediato. Por ejemplo, la tuberculosis pulmonar puede sobrevenir con cualquier cifra de linfocitos T CD4+, y otras afecciones pueden deberse a causas distintas del VIH (por ejemplo, diarrea crónica, fiebre prolongada).

b No se ha determinado con qué concentración exacta de linfocitos T CD4+ $>200 / \mathrm{mm}^{3}$ se debe dar comienzo al tratamiento.

c La recomendación de iniciar el tratamiento antirretroviral en todos los pacientes con enfermedad en estadio III, independientemente del recuento de linfocitos totales, refleja la opinión 


\section{Tabla 3b. Estadificación VIH según OMS para adolescentes y adultos.}

\section{Estadio clínico I:}

\section{Asintomático}

2. Linfadenopatía generalizada

Escala del estado funcional: I (asintomático, actividad normal)

\section{Estadio clínico II:}

3. Pérdida de peso $<10 \%$ del peso corporal

4. Manifestaciones mucocutáneas menores (dermatitis seborreica, prúrigo, onicomicosis, úlceras bucales recurrentes, quelitis angular)

5. Herpes zóster durante los últimos cinco años

6. Infecciones recurrentes de las vias respiratorias superiores (por ejemplo: sinusitis bacteriana)

Y/o escala del estado funcional: 2 ( sintomático, actividad normal)

\section{Estadio clínico III:}

7. Pérdida de peso, $>10 \%$ del peso corporal

8. Diarrea crónica inexplicada, $>1$ mes

9. Fiebre prolongada inexplicada (intermitente o constante), $>1$ mes

10. Candidiasis oral (muguet)

11. Leucoplastia pilosa bucal

12. Tuberculosis pulmonar

13. Infecciones bacterianas graves (por ejemplo: neumonía, piomiositis)

Y/o escala del estado funcional: 3 (ha guardado cama $<50 \%$ del día durante el último mes)

\section{Estadio clínico IV:}

14. Síndrome de emaciación por el $\mathrm{VIH}^{\mathrm{a}}$

15. Neumonía por Pneumocystis carinii

16. Toxoplasmosis cerebral

17. Criptosporidiosis diarreica > I mes

18. Criptococosis, extrapulmonar

19. Enfermedad por citomegalovirus en órganos distintos del hígado, bazo y ganglios linfáticos (por ejemplo: retinitis)

20. Infección por virus del herpes simple, mucocutánea (> I mes) o visceral

21. Leucoencefalopatía multifocal progresiva

22. Cualquier micosis endémica diseminada

23. Candidiasis esofágica, traqueal o bronquial

24. Micobacteriosis atípica, diseminada o pulmonar

25. Septicemia por salmonela no tifoidea

26. Tuberculosis extrapulmonar

\section{Linfoma}

28. Sarcoma de Kaposi

29. Encefalopatía por el $\mathrm{VIH}^{\mathrm{b}}$

Y/o escala del estado funcional: 4 (ha guardado cama $>50 \%$ del día durante el último mes)

a Síndrome de emaciación por el VIH: pérdida de peso $>10 \%$ del peso corporal, más diarrea crónica inexplicada $(>1$ mes) o debilidad crónica y fiebre prolongada inexplicada ( $>1$ mes).

b Encefalopatía por VIH: signos clínicos de disfunción motora o cognitiva discapacitante que interfieren en las actividades de la vida diaria, progresivos durante semanas o meses, en ausencia de una enfermedad o trastorno concomitante distinto de la infección por VIH que explique estos hallazgos. 
Es claro que los pacientes "sintomáticos" tienen un riesgo alto de progresar a SIDA o muerte o ya se encuentran en fase de SIDAy, por lo tanto, en esta población está justificada la iniciación de la terapia antirretroviral independientemente de otros factores pronósticos. Según los estudios sobre factores que pronostican la progresión de la enfermedad, ${ }^{4}$ es claro que tanto la carga viral como el recuento de linfocitos CD4 son importantes. Sin embargo, de los dos el mayor determinante de progresión es el conteo de CD4. Es improbable que un paciente con CD4 $>350$ presente progresión de la enfermedad en el corto o mediano plazo (3-6 meses). Por otro lado, pacientes con recuentos de CD4 bajos $(<200)$ tienen un riesgo alto de progresar a SIDA o muerte, independientemente de la carga viral. Por lo tanto, esta última juega un papel predictivo importante en los pacientes que tienen los CD4 en el rango "no muy bajo-no muy alto" (200 a 350 células).

Varios estudios han intentado determinar el recuento de CD4 más apropiado para iniciar la terapia antirretroviral. Esperar a que sea "muy bajo" puede ser inapropiado, ya que los pacientes pueden progresar a SIDA o muerte, y además pueden tener dificultades para recuperar su sistema inmune. ${ }^{5}$ Según un estudio que utilizó análisis de supervivencia, la cifra ideal de CD4 para iniciar la terapia antirretroviral podría estar alrededor de 275 celulas $/ \mathrm{mm}^{3}{ }^{6}$ Esta es sólo una observación y no debe ser tomada como una verdad, pero es una aproximación a lo que algunos clínicos consideran como adecuado basados en experiencia personal extensa.

Creo que los pacientes con un conteo de CD4 consistentemente $<250$, ameritan la iniciación de terapia antirretroviral, independiente de la carga viral. Este número permite tener una buena opción de recuperación del sistema inmune, con un riesgo bajo de desarrollar infecciones oportunistas. Por el bajo riesgo de progresión de la enfermedad en el corto y mediano plazo en los pacientes con un CD4 $>350$, considero que no requieren iniciar terapia antirretroviral. En ellos, el riesgo de toxicidad de los medicamentos y la limitación en el número y tipo de fármacos utilizables en el futuro, exceden, a mi modo de ver, los posibles beneficios derivados de los antivirales. En aquellos pacientes con cifras de CD4 entre 250 y 350 , utilizo como adjuvante en la toma de la decisión, la carga viral del paciente. Si es muy alta, el riesgo de progresar es mayor. Por lo tanto, si los valores permanecen consistentemente $>100.000$ copias, recomiendo la iniciación de terapia antirretroviral. Lo anterior se resume en la Tabla 4.

\section{Qué iniciar}

Hasta hace un tiempo, la evidencia en favor de un régimen sobre otro era limitada. Hoy existe suficiente información para considerar unos regímenes como "preferibles", y otros como claramente inferiores. La OMS 3 recomienda como primera línea aquellos que contienen NNRTI por encima de los basados en inhibidores de proteasa, por no requerir cadena de frío, su costo favorable y la disponibilidad de algunos de ellos en combinaciones con dosis fijas. La OMS incluye como alternativas preferenciales de inicio alguna de las siguientes:

1) Efavirenz $+3 \mathrm{TC}+(\mathrm{AZT}$ o D4T $)$

2) Nevirapina $+3 \mathrm{TC}+($ AZT o D4T $)$.

La Tabla 5 muestra las recomendaciones del Departamento de Salud de los Estados Unidos (DHHS). ${ }^{2}$ Según esta dependencia se prefieren los basados en combinaciones de dos nucleósidos y efavirenz, o dos nucleósidos y lopinavir/ritonavir.

\begin{tabular}{llll}
\hline \multicolumn{4}{r}{ Tabla } \\
\hline 4. Iniciación de terapia antirretroviral (Opinión personal).
\end{tabular}


Tabla 5. Regímenes recomendados de antirretrovirales para el tratamiento de

pacientes con VIH no expuestos a terapia antirretroviral - DHHS, marzo 2004 (2).

\section{Regímenes basados en NNRTI}

\begin{tabular}{|c|c|}
\hline Régimen preferido & $\begin{array}{l}\text { Efavirenz }+3 T C+(\text { AZT o D4T o Tenofovir), excepto en muj } \\
\text { embarazadas o con potencial de embarazo. }\end{array}$ \\
\hline Regímenes alternativos & $\begin{array}{l}\text { Efavirenz + }(3 T C \circ E T C)+(D D I \circ A B C) \\
\text { Nevirapina + }(3 T C \circ E T C)+(A Z T \circ D D I \circ D 4 T \circ A B C)\end{array}$ \\
\hline \multicolumn{2}{|c|}{ Regímenes basados en PI } \\
\hline Régimen preferido & Lopinavir/ritonavir + 3TC + (AZT o D4T) \\
\hline Regímenes alternativos & 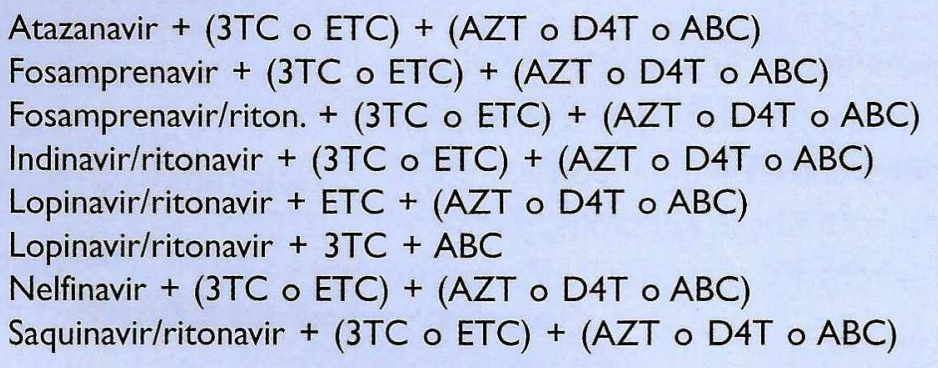 \\
\hline
\end{tabular}

Regímenes basados en 3 NRTI: únicamente para pacientes que no son candidatos a regímenes basados en NNRTI o PI

AZT (o D4T) + 3TC + Abacavir

Hay ensayos clínicos que demuestran la superioridad de efavirenz frente a regímenes basados en nelfinavir, ${ }^{7}$ indinavir ${ }^{8}$ y abacavir. ${ }^{9}$ También hay estudios de cohorte que sugieren que el efavirenz es superior a la nevirapina, ${ }^{10,11}$ y ensayos clínicos que muestran que efavirenz es menos tóxico que la nevirapina. ${ }^{12}$ De manera similar, hay informes que demuestran la superioridad de lopinavir/ritonavir frente a regímenes basados en nelfinavir. ${ }^{13}$ Además, con efavirenz y lopinavir/ritonavir hay investigaciones que muestran la extensión del beneficio de la terapia por tiempo prolongado (tres años para efavirenz y cinco años para lopinavir/ritonavir). El efavirenz debe evitarse en mujeres embarazadas o en edad reproductiva que no utilicen métodos efectivos de anticoncepción, ya que su uso se ha asociado con malformaciones congénitas en primates no humanos. ${ }^{14} \mathrm{El}$ atazanavir es un inhibidor de proteasa con la particularidad de no tener el mismo efecto de clase metabólico (v.g. hiperlipidemias) que otros medicamentos de su clase. Puede ser administrado en una sola dosis diaria y parece tener un perfil de resistencia favorable. Su eficacia ha sido comparable al efavirenz en el manejo de pacientes no previamente expuestos a antirretrovirales (naïve), ${ }^{15}$ y resulta una opción atractiva, teniendo en cuenta que los enfermos con VIH están viviendo más y por lo tanto el riesgo de morir de enfermedades cardiovasculares debe tenerse en cuenta.

En cuanto a la elección de nucleósidos en los regímenes iniciales, hay estudios que favorecen el uso de AZT con 3TC por encima de DDI con D4T. ${ }^{16}$ Además, existe una preocupación adicional por la mayor frecuencia de toxicidad mitocondrial, con síndromes potencialmente fatales como acidosis láctica y esteatosis, utilizando regímenes que contienen DDI y D4T. ${ }^{17}$ Por lo tanto, los nucleósidos de preferencia para incluir en el régimen antirretroviral inicial parecen ser AZT y $3 \mathrm{TC}$.

Es importante recalcar que aunque el régimen de AZT/3TC/Abacavir es conveniente por su relativa baja toxicidad y su comodidad para el paciente, también es inferior en términos de frecuencia de respuesta óptima y tiempo de duración de respuesta óptima, comparado con otros regímenes. ${ }^{9}$ Por lo tanto, debe usarse sólo en forma excepcional en pacientes que no toleren o que no puedan cumplir con otros tratamientos.

En Colombia existe una limitación importante para la iniciación de terapia antirretroviral óptima. Sólo algunos 
medicamentos antirretrovirales están, a la fecha, incluidos en la lista del POS. Ninguno de los dos regímenes preferenciales según el DHHS puede iniciarse con fácilidad en nuestro medio, ya que ni el efavirenz ni el lopinavir/ ritonavir están incluidos en el POS. Por lo tanto, las mejores opciones disponibles de terapia inicial en nuestro medio son:

1) $\mathrm{AZT}+3 \mathrm{TC}+$ Indinavir/Ritonavir

2) $\mathrm{AZT}+3 \mathrm{TC}+$ Nevirapina.

Debe tenerse en cuenta en la toma de decisiones acerca del inicio de estos regímenes, que la nevirapina debe evitarse en mujeres con CD4 altos, con sobrepeso o con pruebas hepáticas de base alteradas, ya que el riesgo de toxicidad severa por nevirapina en estas poblaciones es alto. ${ }^{18}$

Es importante conocer opciones que dentro del marco legal permiten ofrecer el mejor tratamiento disponible, aunque requirieran procedimientos especiales. El artículo $8^{\circ}$ del Acuerdo 228 de 2002, permite que los Comités Técnico Científicos aprueben la formulación de un medicamento no listado en el POS, con manejo de los costos como sigue: "Si el precio de compra de estos medicamentos no incluidos en el manual, teniendo en cuenta el valor total del tratamiento, es igual o menor que el precio de compra de los medicamentos que lo reemplazan o su similar, serán suministrados con cargo a las entidades obligadas a compensar o ARS. Si el precio de compra excede o es superior, la diferencia será cubierta con recursos del Fondo de Solidaridad y Garantía". Esto permite considerar la formulación de efavirenz en lugar de nevirapina, atazanavir en lugar de indinavir/ritonavir, y posiblemente lopinavir/ritonavir en lugar de nelfinavir.

\section{Cómo monitorizar}

La monitorización de pacientes en terapia antirretroviral incluye la evaluación de posibles efectos adversos, y de la calidad de la respuesta a los antirretrovirales.

Los efectos adversos más importantes y los exámenes sugeridos para su monitorización se resumen en las Tablas 6a, 6b, y $6 c$.
La evaluación de la calidad de la respuesta a los antriretrovirales se basa en la monitorización de la carga viral y el conteo de CD4. La respuesta esperada a los antirretrovirales consiste en una disminución importante en la carga viral, y un aumento del conteo de CD4. Si bien este último es el principal determinante del inicio de la terapia, la carga viral es el principal indicador de la respuesta al tratamiento. Se recomienda realizar una carga viral de control entre la tercera y la octava semanas después de iniciar antirretrovirales para evaluar la respuesta al tratamiento. Se considera una respuesta óptima cuando se alcanza un nivel de "indetectable" o cuando el logaritmo de la carga viral disminuye al menos 2 logaritmos en comparación con la carga inicial. ${ }^{19}$

En pacientes que presentan una adecuada respuesta a los antirretrovirales, se recomienda monitorizar el conteo de CD4 y la carga viral en intervalos de tres a seis meses. Es esperable que después de 6 a 12 meses la mayoría de pacientes con adecuada respuesta presenten una carga viral indetectable. ${ }^{20}$

Si la respuesta a antirretrovirales no es óptima, deben sospecharse dificultades en el cumplimiento al tratamiento, intolerancia, problemas farmacocinéticos o resistencia viral. Por ello, en estos pacientes es recomendable hacer un énfasis extremo en la importancia del cumplimiento, optimizar el manejo de los efectos adversos, explorar problemas farmacocinéticos (interferencia con comidas o con otros medicamentos) y planear la realización de una carga viral de control dos meses después de que el paciente se comprometa a tomar las medicinas con excelente cumplimiento. Si la carga viral realizada en ese momento no muestra una disminución de alrededor de 1 logaritmo, debe sospecharse falla terapéutica y se debe considerar el cambio del régimen. Esta decisión nunca debe tomarse a la ligera, ya que tiene implicaciones futuras de suma importancia para el paciente. Por lo tanto, solo debe hacerse después de la asesoría de un experto en el manejo de pacientes con VIH. Aunque en otros ámbitos la decisión de regímenes de segunda línea en los pacientes que han fallado tratamiento inicial se apoya en la realización de pruebas de resistencia viral, en nuestro medio, y en general en países en vía de desarrollo, la realización de pruebas de resistencia viral a nivel del paciente individual es irreal y poco disponible. 


\section{Tabla 6a. Monitorización de pacientes que reciben NRTI.}

\begin{tabular}{|c|c|c|c|}
\hline Antirretroviral & Efecto adverso & Manejo efecto adverso & Monitorización \\
\hline \multirow[t]{2}{*}{ NRTI (Todos) } & $\begin{array}{l}\text { Toxicidad mitocondrial } \\
\text { (acidosis láctica y } \\
\text { esteatohepatosis) } \\
\text { - Efecto de clase }\end{array}$ & $\begin{array}{l}\text { Suspensión tratamiento. } \\
\text { Coenzima Q, Carnitina, } \\
\text { Riboflavina(?) }\end{array}$ & $\begin{array}{l}\text { Medir brecha aniónica y ácido } \\
\text { láctico a pacientes sintomáticos }\end{array}$ \\
\hline & Intolerancia gastrointestinal & $\begin{array}{l}\text { Antieméticos (metoclopramida, } \\
\text { prometazina), Antiácidos. }\end{array}$ & - \\
\hline \multirow[t]{2}{*}{ AZT } & Anemia y/o neutropenia & $\begin{array}{l}\text { Eritropoyetina vs. Suspensión } \\
\text { del medicamento. }\end{array}$ & $\begin{array}{l}\text { Hemoglobina, hematocrito } \\
\text { antes y después de iniciar }\end{array}$ \\
\hline & Cefalea, astenia, insomnio & Acetaminofén, AINES & tratamiento (3-6 meses). \\
\hline \multirow[t]{2}{*}{ D4T } & Neuropatía & $\begin{array}{l}\text { Amitriptilina, gabapentin vs. } \\
\text { suspensión del tratamiento. }\end{array}$ & - \\
\hline & Pancreatitis & Suspensión del tratamiento & Amilasa a pacientes sintomáticos \\
\hline \multirow[t]{2}{*}{ DDI } & Pancreatitis & Suspensión del tratamiento & Amilasa a pacientes sintomáticos \\
\hline & Neuropatía & $\begin{array}{l}\text { Amitriptilina, gabapentin vs. } \\
\text { suspensión del tratamiento. }\end{array}$ & \\
\hline $3 \mathrm{TC}$ & Toxicidad mínima & - & - \\
\hline Abacavir & $\begin{array}{l}\text { Hipersensibilidad (fiebre, } \\
\text { rash, nauseas, diarrea, } \\
\text { astenia, tos) }\end{array}$ & $\begin{array}{l}\text { Suspensión del tratamiento, } \\
\text { NO reiniciar. }\end{array}$ & - \\
\hline Tenofovir & Toxicidad mínima & - & - \\
\hline
\end{tabular}

\section{Tabla 6 b. Monitorización de pacientes que reciben NNRTI.}

\section{Antirretroviral \\ Nevirapina

Efecto adverso
Brote cutáneo (15-30\%)

Hepatitis (mayor riesgo en mujeres, personas obesas, con enfermedad hepática de base, y CD4 elevados).

\begin{tabular}{lll}
\hline Efavirenz & $\begin{array}{l}\text { Brote cutáneo }(5-10 \%) \quad \text { (ver nevirapina) } \\
\text { Hepatitis }\end{array}$
\end{tabular}

Sintomas neuropsiquiátricos

\section{Manejo}

Antihistamínicos. Suspender

si es síndrome de

Steven-Johnson, o si es descamativo o ampolloso.

Suspender tratamiento si es severa.

\section{Monitorización}

-

Enzimas hepáticas antes de iniciar y cada 2-4 semanas por 2-6 meses. 


\section{Tabla 6c. Monitorización de pacientes que reciben PI.}

\begin{tabular}{llll} 
Antirretroviral & Efectos adversos & Manejo & Monitorización \\
\hline PI (Todos) & $\begin{array}{l}\text { Hiperlipidemias, } \\
\text { hiperglucemia (excepto } \\
\text { atazanavir) } \\
\begin{array}{l}\text { Lipodistrofia } \\
\text { Posible riesgo incrementado ejercicio, gemfibrozilo, } \\
\text { de sangrado en hemofilicos } \\
\text { Intolerancia gastrointestinal }\end{array}\end{array}$ & $\begin{array}{l}\text { Cambio de régimen(??), } \\
\text { cirugía plástica }\end{array}$ & $\begin{array}{l}\text { Perfil lipídico, y glucosa de base } \\
\text { y cada 3-4 meses. }\end{array}$ \\
& $\begin{array}{l}\text { Metoclopramida, loperamida, } \\
\text { dependiendo de Pl se puede } \\
\text { o no usar antiácidos } \\
\text { Cambiar régimen si severa }\end{array}$ & - \\
& Transaminitis/hepatitis & $\begin{array}{l}\text { Considerar medición periódica } \\
\text { de enzimas hepáticas }\end{array}$ \\
\hline
\end{tabular}

\begin{tabular}{lll}
\hline Indinavir & $\begin{array}{l}\text { Nefritis intersticial, } \\
\text { urolitiasis }\end{array}$ & $\begin{array}{l}\text { Manejo agudo, cambiar régimen. } \\
\text { Prevenir tomando más de } \\
1.5 \mathrm{~L} / \mathrm{d} .\end{array}$ \\
$\begin{array}{l}\text { Xeroftalmia, xerosis, } \\
\text { paroniquia. }\end{array}$ & $\begin{array}{l}\text { Lubricantes locales } \\
\text { Hiperbilirrubinemia } \\
\text { indirecta }\end{array}$ & $\begin{array}{l}\text { No requiere manejo (sin } \\
\text { consecuencias clínicas) }\end{array}$ \\
\hline Ritonavir & Parestesias & $\begin{array}{l}\text { Cambiar régimen si no es } \\
\text { tolerable }\end{array}$
\end{tabular}

Perversión del gusto

Miositis, hiperuricemia,

hepatitis

\begin{tabular}{lll}
\hline Nelfinavir & $\begin{array}{l}\text { Diarrea }(10-30 \%) \\
\text { Transaminitis }\end{array}$ & Calcio oral, loperamida \\
\hline Saquinavir & Hipoglucemia en diabéticos & Manejo agudo. \\
& Cefalea & Acetaminofén. \\
\hline Amprenavir & Brote cutáneo & Cambiar régimen si no tolera. \\
& Parestesias &
\end{tabular}

Lopinavir/rit Astenia

De tener a mano dicha prueba, es recomendable guiar cambios en la terapia que se crean debidos a falla terapéutica mediante la evaluación de resistencia. Para ello es de crucial importancia realizar la prueba de resistencia sólo si el paciente está expuesto consistentemente a los antirretrovirales, ya que de no ser así el "virus salvaje" constituiría el tipo predominante al hacer la prueba, y los resultados no reflejarían el virus que predominaría cuando el paciente está bajo el efecto de medicinas.
En pacientes que han presentado falla terapéutica a dos o tres regímenes de antirretrovirales, la posibilidad de lograr respuestas óptimas es mucho menor. De hecho, en estos casos el objetivo primario de lo que se llama "terapia de rescate" no es ya lograr una carga viral indetectable sino mantener cierto grado de supresión viral que permita al sistema inmune (conteo de CD4) mantenerse en niveles que impidan el desarrollo de infecciones o tumores oportunistas. 


\section{Generalidades sobre cambios y ajustes de terapia antirretroviral}

Antes de cambiar uno o más componentes de un régimen de antirretrovirales, la circunstancia debe analizarse con cuidado. Esto es de suma importancia, ya que entre a más antirretrovirales se exponga un paciente, menos probable es tener éxito a largo plazo. Siempre debe considerarse la posibilidad de que la falla terapéutica sea consecuencia de problemas de cumplimiento, tolerancia o farmacocinética. Las dos indicaciones para cambiar terapia antirretroviral son la intolerancia/toxicidad severas y la falla terapéutica. Cuando se hace como consecuencia de intolerancia/toxicidad, se puede cambiar sólo el medicamento que no está siendo tolerado, pero si se va a realizar como resultado de falla terapéutica, se debe procurar cambiar todo el régimen.

Cuando un paciente ha fallado el primer régimen, la escogencia del segundo puede basarse en el historial de exposición y si es posible en pruebas de resistencia viral. En general, hoy en día se recomienda evitar la combinación DDI y D4T por razones ya expuestas, aunque no debe descartarse del todo. La combinación de D4T y AZT está contraindicada. La Tabla 7 muestra los lineamientos generales para escoger regímenes de segunda línea en pacientes que han fallado la terapia de primeralínea.

Los siguientes son principios generales para tener en cuenta cuando se considera cambiar uno o más componentes de un régimen antirretroviral:

1) Antes de considerar el cambio de un antirretroviral por toxicidad o intolerancia, procure minimizar esos efectos indeseables, si es necesario con manejo médico.
2) Antes de considerar cambiar un régimen por falla terapéutica, confirme la falla virológica después de optimizar el cumplimiento del paciente.

3) Antes de decidir un cambio de antirretrovirales, consulte a un experto en el manejo del VIH.

4) Nunca cambie un solo antirretroviral en un régimen que está fallando.

5) Nunca añada un antirretroviral a un régimen que ha tenido respuesta subóptima. La única excepción es añadir ritonavir a un régimen basado en inhibidor de proteasa, en un paciente que tiene carga viral cercana a indetectable.

6) Para decidir cambios en la terapia antirretroviral es de suma importancia conocer la historia de exposición a antirretrovirales que ha tenido el paciente.

7) Cuando un régimen esté fallando, cámbielo en su totalidad, de ser posible, o procure añadir tres o más medicamentos a los que el paciente no haya tenido exposición. Si no es posible, escoja el mayor número de fármacos a los que el paciente no haya sido expuesto, $y$ trate de utilizar inhibidores de proteasa potentes (saquinavir/ritonavir, lopinavir/ritonavir, o saquinavir/lopinavir/ritonavir).

8) Cuando un paciente ha tenido falla terapéutica con NNRTI (nevirapina o efavirenz), asuma que el virus tiene resistencia cruzada contra toda la clase.

9) Siempre que sea posible, procure utilizar pruebas de resistencia viral para la escogencia del nuevo régimen antirretroviral.

10) Cuando ordene una prueba de resistencia viral por genotipificación pensando en cambiar un régimen,

\section{Tabla 7. Selección de regímenes de segunda línea basados en componentes} de régimen inicial para pacientes con falla terapéutica.

\section{Régimen que falla}

AZT (o D4T) + 3TC (o ETC) + Efavirenz (o Nevirapina)
$A Z T$ (o D4T) + 3TC (o ETC) + Inhibidor proteasa
$D D I+3 T C$ (o ETC) + Efavirenz (o Nevirapina)
$D D I+3 T C$ (o ETC) + Inhibidor proteasa

\section{Régimen de segunda línea}

Abacavir (o tenofovir) + DDI + Inhibidor proteasa

Abacavir (o tenofovir) + DDI + Efavirenz (o Nevirapina)

AZT (o D4T) + Abacavir + Inhibidor proteasa

AZT (o D4T) + Abacavir + Efavirenz (o Nevirapina) 
asegúrese de que el paciente está tomando con juicio el régimen que está fallando, en el momento en que se le extrae la sangre para la prueba de genotipificación. De lo contrario la prueba será inútil.

11) Nunca decida cambios de régimen por valores únicos de laboratorio. Para documentar falla inmunológica repita CD4, para documentar falla virológica repita carga viral.

\section{El cumplimiento como componente fundamental de la terapia antirretroviral}

El cumplimiento es un requisito fundamental para el éxito de la terapia antirretroviral. Es por eso que se debe siempre explorar la disposición psicológica que tenga un paciente para someterse a la terapia antirretroviral.

Para que el paciente pueda tomar una decisión informada acerca de la iniciación o no de terapia antirretroviral, debe explicársele con claridad lo siguiente:

1) Que la terapia antirretroviral es efectiva para disminuir la mortalidad, y que hoy en día los pacientes con VIH pueden tener larga vida gracias a estas medicinas.

2) Que existen estudios clínicos que han demostrado una correlación clarísima entre cumplimiento y respuesta óptima, ${ }^{21}$ y que por lo tanto la meta es que cumpla con el 100\% de las dosis (Tabla 8). Debe entender que la respuesta inadecuada por falta de cumplimiento es el preámbulo de una respuesta inadecuada por resistencia viral, y que un virus que ya

Tabla 8. Correlación entre cumplimiento

al tratamiento y frecuencia de respuesta óptima al mismo (21).

\begin{tabular}{cc}
$\begin{array}{c}\text { Cumplimiento al } \\
\text { tratamiento (No dosis } \\
\text { tomadas/No dosis } \\
\text { prescritas) }\end{array}$ & $\begin{array}{c}\text { Carga viral } \\
\text { indetectable }(<400 \\
\text { copias) a los } 6 \text { meses }\end{array}$ \\
\hline$<95 \%$ & $78 \%$ \\
$90-95 \%$ & $45 \%$ \\
$80-90 \%$ & $33 \%$ \\
$70-80 \%$ & $29 \%$ \\
$<70 \%$ & $18 \%$
\end{tabular}

ha sido expuesto a medicinas y que es potencialmente resistente, es mucho más difícil de controlar.

3) Que es muy probable que tenga efectos adversos a los medicamentos, y por lo tanto debe estar preparado para hacer un esfuerzo para cumplir a pesar de cierto grado de incomodidad e intolerancia (debe conocer los efectos secundarios más esperables según el régimen escogido).

4) Que de presentar efectos adversos incómodos, debe acudir a su equipo de trabajadores de la salud para explorar alternativas para minimizar esos efectos.

5) Que va a tener que tomar un número significativo de píldoras o cápsulas por horario.

6) Que siempre existen interacciones con otros fármacos y sustancias, y por lo tanto la toma de drogas o medicamentos (aún si son "naturistas" o vitaminas) debe siempre comentarse con el médico.

7) Que ciertas medicinas tienen interacciones con comidas, y eso debe discutirse con el médico o la enfermera si decide iniciar tratamiento.

8) Que el éxito del tratamiento está prácticamente “en sus manos".

Una vez el paciente ha sido informado de todo lo anterior, debe dársele la oportunidad de decidir, según crea estar listo para iniciar el tratamiento. Si no está listo para enfrentarse a todo lo que implica iniciar la terapia, es conveniente aplazar el inicio de la misma. Por lo complejo de la decisión de iniciar terapia antirretroviral, ésta es una decisión que en general debe tomarse en la consulta ambulatoria y solo en forma excepcional con el paciente hospitalizado.

Existen situaciones que favorecen el incumplimiento de la terapia. Problemas psicológicos o psiquiátricos (depresión, uso de alcohol u otras drogas psicoactivas) deben manejarse a tiempo para evitar que impacten el cumplimiento del tratamiento. Al paciente se le deben mencionar ayudas simples que pueden facilitarle el cumplimiento con el tratamiento, como son el llevar siempre consigo medicinas cuando salga de su casa, y el utilizar alarmas que le recuerden la toma del medicamento. 
Siempre que el paciente asista a control médico se debe tocar el tema del cumplimiento para tomar medidas correctivas a tiempo, de ser necesarias.

\section{Referencilas}

1. UNAIDS/WHO. Colombia: Epidemiological fact sheet on HIV/AIDS and sexually transmitted diseases. (Citado 2002). Disponible en: PDF htpp://www.who.int/emchiv/fact sheets/ pdfs/Colombia.

2. «Terapia antirretroviral». Disponible en PDF. http:// aidsinfo.nih.gov/quidelines/adult/AA 032304.

3. «Terapia antirretroviral».Disponible en PDF. http:/// www.who.int/hiv/pub/prev care/en/arvrevisionsp.

4. Egger M, May M, Chene G, et al. Prognosis of HIV-1-infected patients starting highly active antiretroviral therapy: a collaborative analysis of prospective studies. Lancet 2002;360(9340):1178

5. Florence E, Lundgren J, Dreezen C, et al. Factors associated with a reduced CD4 lymphocyte count response to HAART despite full viral suppression in the EuroSIDA study. HIV Medicine 2003;4(3):255-62.

6. Ahdieh-Grant L, Yamashita TE, Phair JP, et al. When to Initiate Highly Active Antiretroviral Therapy: A Cohort Approach. Am J Epidemiol 2003;157:738-46.

7. Albrecht MA, Bosch RJ, Hammer SM, et al. Nelfinavir, efavirenz, or both after the failure of nucleoside treatment of HIV infection. N Engl J Med. 2001;345(6):398-407.

8. Staszewski S, Morales-Ramirez J, Tashima KT, etal. Efavirenz plus zidovudine and lamivudine, efavirenz plus indinavir, and indinavir plus zidovudine and lamivudine in the treatment of HIV-1 infection in adults. Study 006 Team. N Engl J Med. 1999;341(25):1865-73.

9. Gulick RM, Ribaudo HJ, Shikuma CM, et al. ACTG 5095: A comparative study of 3 protease inhibitor-sparing antiretroviral regimens for the initial treatment of HIV infection. In: International AIDS Society Abstracts of the 2 nd Conference on HIV Pathogenesis and Treatment; 2003 Jul 13-16; París Francia. París 1992.Abstractno.41
10. Cozzi-Lepri A, Phillips AN,D'Arminio Monforte A, et al. Virologic and immunologic response to regimens containing nevirapine or efavirenz in combination with 2 nucleoside analogues in the Italian Cohort Naïve Antiretrovirals study. $\mathrm{J}$ Infect Dis 2002; 185:1062-69.

11. P Keiser, N Nassar, C White, G Koen, Moreno S. Comparison of nevirapine- and efavirenz-containing antiretroviral regimens in antiretroviral-naive patients: a cohort study. HIV Clin Trials 2002; 3:296-303.

12. Van Leth F, Phanuphak P, Ruxrugtham K, et al. Comparison of first-line antiretroviral therapy with regimens including nevirapine, efavirenz, or both drugs, plus stavudine and lamivudine: a randomized open-label trial, the 2NN Study. Lancet 2004;363: 1253-63.

13. Walmsley S, Bernstein B, King M, et al. Lopinavir-ritonavir versus nelfinavir for the initial treatment of HIV infection. $\mathrm{N}$ Engl J Med 2002;346(26):2039-46.

14. Sustiva. Package insert. T4-B0001A-10-03. Princenton, NJ, Bristol-Myers Squibb Company: 2003.

15. A phase III study comparing the antiviral efficacy and safety of BMS-232632 (ATV) with efavirenz (EFV), each in combination with fixed dose zidovudine-lamivudine (ZDV+3TC).Princeton, NJ Bristol-Myers Squibb Company.

16. ACTG 384. XIV International AIDS Conference, Barcelona 2002, Abstracts LB20a and LB20b.

17. Boubaker K, Flepp M, Sudre P, et al. Hyperlactatemia and antiretroviral therapy: the Swiss HIV Cohort Study. Clin Infect Dis 2001; 33(11): 1931-7.

18. New nevirapine label underscores the risk for hepatotoxicity in key populations. AIDS Clinical Care 2004;16(3):2.

19. Maggiolo F, Migliorino M, Pirali A, Pravettoni G, Caprioli S, Suter F. Duration of viral suppression in patients on stable therapy for HIV-1 infection is predicted by plasma HIV RNA level after 1 month of treatment. J Acquir Immune Defic Syndr 2000;25(1):36-43.

20. Raboud JM, Rae S, Montaner JS. Predicting HIV RNA virologic outcome at 52-weeks follow-up in antiretroviral clinical trials. The INCAS and AVANTI Study Groups. J Acquir Immune Defic Syndr 2000;24(5):433-9.

21. Paterson DL, Swindells S, Mohr J, et al. Adherence to protease inhibitor therapy and outcomes in patients with HIV infection. Ann Intern Med. 2000;133(1):21-30.

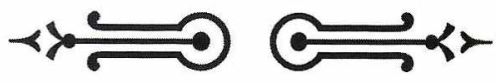

